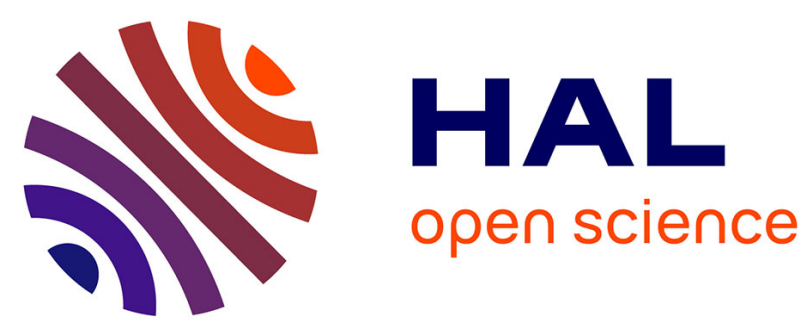

\title{
Parental anxiety before invasive cardiac procedure in children with congenital heart disease: Contributing factors and consequences
}

Oscar Werner, Fedoua El Louali, Virginie Fouilloux, Pascal Amedro, Caroline Ovaert

\section{To cite this version:}

Oscar Werner, Fedoua El Louali, Virginie Fouilloux, Pascal Amedro, Caroline Ovaert. Parental anxiety before invasive cardiac procedure in children with congenital heart disease: Contributing factors and consequences. Congenital Heart Disease, 2019, 14 (5), pp.778-784. 10.1111/chd.12777 . hal02123842

\section{HAL Id: hal-02123842 \\ https://hal.science/hal-02123842}

Submitted on 25 Jun 2020

HAL is a multi-disciplinary open access archive for the deposit and dissemination of scientific research documents, whether they are published or not. The documents may come from teaching and research institutions in France or abroad, or from public or private research centers.
L'archive ouverte pluridisciplinaire HAL, est destinée au dépôt et à la diffusion de documents scientifiques de niveau recherche, publiés ou non, émanant des établissements d'enseignement et de recherche français ou étrangers, des laboratoires publics ou privés. 


\title{
Parental anxiety before invasive cardiac procedure in children with congenital heart disease: Contributing factors and consequences
}

\author{
Oscar Werner MD ${ }^{1} \quad$ | Fedoua El Louali MD² | Virginie Fouilloux MD, $\mathrm{PhD}^{3}$ | \\ Pascal Amedro MD, $\mathrm{PhD}^{1,4}$ | Caroline Ovaert MD, $\mathrm{PhD}^{2,5}$
}

\begin{abstract}
${ }^{1}$ Pediatric and Congenital Cardiology Department, M3C Regional Reference CHD Centre, University Hospital, Montpellier, France

${ }^{2}$ Pediatric and Congenital Cardiology, M3C Regional Reference CHD Centre, University Hospital, Marseille, France

${ }^{3}$ Pediatric and Congenital Cardiac Surgery, University Hospital, Marseille, France

${ }^{4}$ PHYMEDEXP, CNRS, INSERM, University of Montpellier, Montpellier, France

${ }^{5}$ Marseille Medical Genetics, INSERM UMR 1251, Aix Marseille University, Marseille, France
\end{abstract}

Correspondence

Oscar Werner, Pediatric and Congenital Cardiology Department, Montpellier University Hospital, 371 Avenue du Doyen Giraud, 34295 Montpellier, France. Email: o-werner@chu-montpellier.fr

\begin{abstract}
Objective: Medical information provided to parents of a child with a congenital heart disease can induce major stress. Visual analog scales have been validated to assess anxiety in the adult population. The aim of this study was to analyze parental anxiety using a visual analog scale and to explore the influencing factors.

Design: This prospective cross-sectional study.

Setting: Tertiary care regional referral center for congenital heart disease of Marseille-La Timone university hospital.

Patients: Parents of children with a congenital heart disease, as defined by the ACCCHD classification, referred for cardiac surgery or interventional cardiac catheterization, were offered to participate.

Intervention and outcome measure: The parental level of anxiety was assessed using a visual analog scale (0-10) before intervention and after complete information given by the cardiologist, the surgeon or the anesthetists.

Results: Seventy-three children [7 days-13 years], represented by 49 fathers and 71 mothers, were included in the study. A total of 42 children required cardiac surgery and 31 children underwent interventional cardiac catheterization. The mean score of maternal anxiety was significantly higher than the paternal anxiety $(8.2$ vs $6.3, P<.01)$. A high level of maternal anxiety (visual analog scale $>8$ ) was associated with paternal anxiety $(P=.02)$, the child's comorbidity $(P=.03)$, the distance between home and referral center $(P=.04)$, and the level of risk adjustment for congenital heart surgery $(P=.01)$. In multivariate analysis, maternal anxiety was associated with paternal anxiety (OR $=4.9 ; 95 \%$ confidence interval [1.1-19.2]), and the level of risk adjustment for congenital heart surgery $(O R=11.4 ; 95 \%$ confidence interval [1.2-116.2]). No significant association was found between parental anxiety and prenatal diagnosis.

Conclusion: This study highlighted several factors associated with the parental anxiety. Identifying the parents at risk of high stress can be useful to set up psychological support during hospitalization.
\end{abstract}

KEYWORDS

anxiety, congenital heart disease, parents, visual analog scale 


\section{1 | INTRODUCTION}

Congenital heart disease (CHD) is the leading cause of congenital defects in children, with an incidence of $0.8 \%$ of living births. ${ }^{1}$ In the past three decades, tremendous progress in patient's management has significantly improved the overall prognosis, and, consequently, transferred the mortality in CHD from childhood to adulthood. ${ }^{2}$ As a result, after focusing on the survival of children with $\mathrm{CHD}$, more attention is currently being given to health-related quality of life and psychological well-being of the children and their parents. ${ }^{3,4}$ Indeed, despite these great advances, psychological trauma is not uncommon for CHD survivors. ${ }^{5}$ Moreover, we recently showed that the quality of life was impacted by the number of invasive procedures and the level of anxiety in the CHD population. ${ }^{6,7}$

Many children with $\mathrm{CHD}$ will undergo one or several high-risk invasive procedures, such as cardiac surgery and/or interventional cardiac catheterization. ${ }^{8,9}$ Such events represent major disruptions within the family circle and parental psychological trauma may occur soon after prenatal or postnatal diagnosis. ${ }^{10} \mathrm{~A}$ recent review of more than 30 articles noticed the impact of a cardiac surgery on the parental mood after prenatal diagnosis and this even far after the birth. ${ }^{11}$ When focusing on the parents' perspective, we recently found that the parental assessment of the child well-being was more pejorative than the child self-reported well-being, ${ }^{12}$ with relevant differences between fathers' and mothers' assessments. ${ }^{13}$ However, we did not evaluate the level of parental anxiety.

When considering the impact of CHD diagnosis on the parental psychological state, some studies stated that posttraumatic stress disorders were observed in more than $30 \%$ of the parents, with major depressive episodes in $25 \%-50 \%$ of cases. ${ }^{3-5}$ The psychological well-being of the parents has been considered as a major factor influencing the psychological state of the expected child, sometimes above the CHD severity itself. ${ }^{14}$ We also have to take into account that maternal anxiety during pregnancy can have consequences on long-term child neurodevelopment. ${ }^{15}$ Therefore, improving the parents' psychological well-being has become a priority for health care CHD professionals and more attention has been given on how medical information is delivered to parents before and after birth. The daily presence of a psychologist in a pediatric cardiology unit seems mandatory but many units do not have this facility. Knowing this, we have to optimize their presence in referring the families that will the most benefit from their help.

Assessing the level of anxiety in parents of children with CHD is of interest but remains time consuming for medical staff and patients, especially when using the existing instruments. Indeed, the 31-item perinatal anxiety screening scale (PASS) and the 21-item depression, anxiety and stress scale (DASS 21) both require a minimum of 20 minutes to be completed. ${ }^{5,6}$ These specialized anxiety scales have as such mainly been used in clinical research but only rarely on a routine basis. ${ }^{16}$ At the opposite, the analogic visual scale (AVS) has been largely used as a simple, reproducible, and validated instrument for adult anxiety assessment in routine health care. ${ }^{17}$ So far, it has not been used to assess anxiety of parents facing disease in their offspring.
Our study aimed to assess the level of parental anxiety before an invasive cardiac intervention, using the AVS instrument, in a population of children with CHD. We also intended to identify associations between parental anxiety and clinical or social determinants in this specific population.

\section{MATERIAL AND METHODS}

\section{1 | Study design}

This prospective cross-sectional study was carried out from January 2017 to May 2017 in the pediatric cardiology and pediatric intensive care units of "La Timone Enfants" Marseille, France. This tertiary care university hospital is the regional referral CHD center in Southern France (about 7 million inhabitants).

\section{2 | Participants}

Children with a CHD, as defined by the ACC-CHD classification, aged from 0 to 15 years old, and referred for cardiac surgery or interventional cardiac catheterization, were screened. Their parents were offered to participate in the study, when at least one parent was available to answer the questionnaire. Parents unable to answer the questionnaire were not eligible.

\section{3 | Instrument for anxiety assessment}

The AVS instrument was used for anxiety assessment. ${ }^{17}$ This scale ranges from 0 (total absence of anxiety) to 10 (maximal level of anxiety). The AVS has been validated in previous studies comparing it with more complex anxiety scales. ${ }^{17-19}$ Parental anxiety assessment using the AVS requires less than 5 minutes.

The AVS anxiety assessment relied on the following question asked by the investigator to each parent, separately: "Using a score from 0 to 10, how high would you set your level of anxiety with regards to your child's coming intervention? The score 0 corresponds to the absence of any anxiety and the score 10 corresponds to the maximal level of anxiety you can imagine".

The questionnaire was presented to one or to both parents, according to their availability during the preintervention outpatient visit with the pediatric cardiologist (less than 1 month before the hospitalization). It is off note that a surgical and anesthetist visit was always preceding the anxiety assessment. When both parents were willing to participate in the study, they were asked to fill in the questionnaire separately.

\section{4 | Clinical data}

Medical information were extracted from the patient's medical records. They included the time of diagnosis (prenatal or postnatal), the cardiac history with the number of cardiac interventions, cardiac comorbidities, and current treatment. The severity of the CHD was classified into four groups, as previously described by Uzark et al (Table 1). ${ }^{20}$ 
TAB LE 1 CHD severity classification

Severity class 1: Mild CHD requiring no therapy or effectively treated nonoperatively (catheter therapy)

Severity class 2: Moderate CHD requiring no therapy or surgically corrected (curative)

Severity class 3: Surgically treated CHD with significant residua or need for additional surgery

Severity class 4: Complex or severe CHD, uncorrectable or palliated (includes single ventricle

The level of risk adjustment for congenital heart surgery (RACHS-1) was recorded. This six-category score is routinely used in our institution during preanesthesia evaluation clinic and takes into account the complexity of the CHD, the age ( $<$ or $>30$ days), and the complexity of the intervention. ${ }^{21}$

\section{5 | Sociodemographic data}

Sociodemographic parameters were also collected from the patient medical records and included the type of parental job, the existence of siblings in the family, and the CHD center distance from home.

\section{6 | Ethics}

The study was conducted in compliance with the Good Clinical Practices protocol and Declaration of Helsinki principles. It belongs to a multicenter European research program dedicated to quality of life among children with CHD and was approved by the South Mediterranean IV Ethics Committee (2009-A00423-54). Informed consent was obtained from all parents.

\section{7 | Statistical analysis}

Results were presented using median and range, or mean and standard deviation (SD) for continuous variables, and frequencies and proportions for categorical variables. The continuous variable distributions were tested using the Kolmogorov-Smirnov test.

The two following conditions were compared: low or moderate parental anxiety (AVS < 8) and high parental anxiety (AVS equal or $>8) .{ }^{18}$ We used the $\chi^{2}$ test or Fisher's exact test (if appropriate) for categorical variables and Mann-Whitney test for continuous variables.

Multiple regression model was created using variables identified in high parental anxiety on univariate analysis. $P$ values $<.05$ were considered statistically significant. All analyses were performed using the SPSS 11.0 software (SPSS, Inc, Chicago, IL, USA).

\section{3 | RESULTS}

\section{1 | Population}

During the 5-month study period, 205 children with a CHD underwent an invasive cardiac procedure in our institution (82 interventional catheterization procedures and 123 surgical interventions). None of the families refused to participate, but for 115 children, parents were not available and for 17 , they were unable to understand the question (language barrier). A total of 73 families were included in the study (49 fathers, 71 mothers), representing $36 \%$ of the overall admissions for cardiac invasive intervention in our institution during the study period. There were more female (60\%) than male patients. Median age was 11 months (range 7 days-13 years). The diagnosis was prenatal in $34 \%$ of the whole population and in 55\% of the more severe heart diseases (severity classes 3 and 4). The prenatal diagnosis was made at an early stage of the pregnancy ( $<26$ weeks) in $70 \%$ of the patients. Mean hospital stay was $8.8 \pm 7.8$ days. More than half $(54 \%)$ of all patients required an admission in intensive care unit (ICU) after the intervention. The mean ICU length of stay was $7.3 \pm 8.8$ days. The majority of patients (87\%) who underwent interventional cardiac catheterization did not require intensive care after the intervention. Main population characteristics are reported in Table 2 .

\subsection{Parental anxiety}

A total of 120 parents (71 mothers and 49 fathers) filled in the anxiety AVS instrument. Both parents were present for 47 patients (64\%). The mean score of parental anxiety was $7.6 \pm 2.1$. The mean score of anxiety was significantly higher in mothers than in fathers $(8.2 \pm 1.5$ vs $6.9 \pm 2.1$, respectively, $P<.01)$.

In univariate analysis, factors that were significantly associated with maternal anxiety were: the level of paternal anxiety, the presence of comorbidity, the distance between home and the surgical center, and the RACHS-1 score (Table 3). In multivariate analysis, the mothers were 11 times more likely to report a high level of anxiety when their children belonged to high RACHS-1 categories and 4.9 times more likely to report a high level of anxiety when the father had an anxiety AVS of more than 8 over 10 (Table 4).

The only factor that significantly influenced the father's anxiety in univariate analysis was the distance between home and the surgical center, but this association was not confirmed in multivariate analysis (Table 5).

No significant association was found between the parental anxiety level and the moment of diagnosis (prenatal vs postnatal), among the neonatal and young infant population ( $<3$ months old).

\section{4 | DISCUSSION}

From a cohort of 73 families of children with a CHD, this study reported the level of parental anxiety before their child underwent cardiac surgery or interventional catheterization, and using, for the first time in this population, the AVS instrument.

In previous studies, the AVS instrument was found to be reliable for assessing pain or anxiety in adult patients and has been routinely used in conditions such as anxiety and occupational stress at work, ${ }^{17}$ anxiety before anesthesia for dental surgery, ${ }^{22}$ etc. However, the 
TABLE 2 General population

$\begin{array}{ll}\text { Characteristics } & n=73 \\ \text { Sociodemographic } & \\ \text { Sex (female), } n(\%) & 45(61.6) \\ \text { Age in months, med [Quart] } & 11[3-54] \\ \text { Weight in kg, med [Quart] } & 7.8[4.3-16.6] \\ \text { Height in cm, med [Quart] } & 71[57-106] \\ \text { Presence of siblings, } n \text { (\%) } & 42(64.6) \\ \text { Level of maternal education, } n(\%) & 21(42.9) \\ \text { Distance from home to surgical center in km, } & 98[26-168] \\ \text { mean [Quart] } & \end{array}$

\section{Medicals}

Antenatal diagnosis, $n$ (\%)

25 (35)

Severity score, $n$ (\%)

1

$17(23,6)$

2

25 (34.7)

3

28 (38.9)

4

Comorbidities, $n$ (\%)

History of past surgeries or ICC, $n$ (\%)

$18(24.7)$

Patient under medication, $n$ (\%)

$27(37.5)$

CHD classification, $n(\%)$

Tetralogy of Fallot

Pulmonary atresia with open septum

3 (4)

Transposition of the great arteries

$4(5,4)$

Aortic coarctation

$12(16,4)$

Ventricular septal defect

$7(9,5)$

Atrial septal defect

$10(13,5)$

Atrioventricular canal defect

$2(2,7)$

Persistent ductus arteriosus

Pulmonary arterial stenosis

3(4)

Other CHD

14 (19)

Intervention

Surgeries, $\boldsymbol{n}(\%)$

41 (56.9)

CBP, $n(\%)$

32 (78)

Surgical risk score (RACHS), $n$ (\%)

1

$5(12,1)$

2

$9(21,9)$

3

$20(48,9)$

4

5

$1(2,4)$

Unclassified

$2(4,8)$

Journey in intensive care unit, $n$ (\%)

$42(60.9)$

Days with mechanical ventilation in days, med

[Quart]

Days of hospitalization in intensive care unit, med [Quart]

Medical complication, ${ }^{\mathrm{a}} \mathrm{n}(\%)$

$7[3-11]$

$40(54,7)$
TABLE 2 (Continued)

\begin{tabular}{|ll|}
\hline Characteristics & $\mathbf{n}=\mathbf{7 3}$ \\
\hline Cardiovascular complication & $12(16,4)$ \\
\hline Rhythmic complication & $8(10,9)$ \\
\hline Pericardial complication & $1(1,3)$ \\
\hline Pulmonary complication & $8(10,9)$ \\
\hline Infectious complication & $7(9,5)$ \\
\hline Other complication & $4(5,4)$
\end{tabular}

Values are mean \pm SD, $N(\%)$ or median (quart).

Abbreviations: $\mathrm{CPB}$, circulatory pulmonary bypass; SD, standard deviation.

${ }^{a} A$ patient can have multiple events.

use of AVS for anxiety assessment in parents of children with a chronic disease has not been reported yet, to our knowledge. In a situation of high parental stress, such as before an invasive or highrisk procedure planned for their child, the AVS stands as a simple measurement tool for parental anxiety assessment.

Our results are interesting because they point several risk factors of parental anxiety that could help the medical staff to personalize the psychological care. The level of anxiety in mothers was significantly more important than in fathers. This is in line with previous studies reporting a high level of maternal anxiety regardless of the time in the medical history of the child (at diagnosis, before surgery....). ${ }^{23}$ Similarly, after a prenatal diagnosis of a congenital anomaly, Skari et al have observed a higher level of stress at birth in mothers than in fathers (66\% vs 39\%, respectively). ${ }^{24}$ According to Skreden et al, the level of parental anxiety remains increased 9 years after their child's malformation has been diagnosed, and that for $36 \%$ of mothers and $23 \%$ of fathers. ${ }^{25}$ In their study, Pomicino et al focused on the level of parental anxiety immediately before surgery. They also measured a higher level of anxiety in mothers than in fathers $(O R=4.7 ; P=.01) .{ }^{26}$ It is of note that these four studies included all congenital malformations, and not only CHD. Nevertheless, according to Pomicino et al, the level of parental anxiety was higher in CHD than in other congenital anomalies. ${ }^{26}$

Interestingly, our study found that the level of maternal anxiety was impacted by the father's anxiety. Indeed, the more a father was anxious, the more the mother was too (OR of 4.9). Most of the time, the mother remains the principal spokesperson during a child's hospitalization. ${ }^{27}$ Nevertheless, more than two thirds of fathers participated in this study and their mean level of anxiety reached nearly 7 out of 10 . In the current era, fathers of children with a CHD have been increasingly involved in their child's health condition, and they accurately evaluate their child's quality of life, as we recently reported. ${ }^{13}$ In the literature, more attention has been given to father reports in psychosocial studies. Indeed, Woolf-King et al recently reported that posttraumatic stress syndrome remains present in $10 \%$ of fathers, 6 months after their child underwent cardiac surgery. ${ }^{11}$ In their study, the main factor associated with posttraumatic stress syndrome was a low level of quality of life, in its mental health component, at the time of hospital discharge. ${ }^{11}$ 


\begin{tabular}{|llll|} 
& $\begin{array}{l}\text { Maternal anxiety } \\
>\text { or }=\text { to } 8 / 10\end{array}$ & $\begin{array}{l}\text { Maternal } \\
\text { anxiety }<8 / 10\end{array}$ & P value \\
\hline$n=71$ & $N=36$ & $N=35$ & .02 \\
\hline Paternal AVS, moy \pm SD & $7.6 \pm 1.9$ & $6.1 \pm 2.1$ & .03 \\
\hline RACHS $>3, n(\%)$ & $5(13.9)$ & $0(0)$ & .04 \\
\hline $\begin{array}{l}\text { Distance from home to surgical } \\
\text { center in km, médian [Quart] }\end{array}$ & $106[0.1-149]$ & $56[29-202]$ & .01 \\
\hline $\begin{array}{l}\text { Comorbidity, } n \text { (\%) } \\
\text { Prenatal diagnosis, } n \text { (\%) }\end{array}$ & $15(41.6)$ & $6(17.1)$ & .46 \\
\hline Surgery vs ICC, $n$ (\%) & $21(58.3)$ & $13(37.1)$ & .43 \\
\hline $\begin{array}{l}\text { Siblings, } n \text { (\%) } \\
\text { Delay between diagnostic and } \\
\text { intervention }>1 \text { year, } n \text { (\%) }\end{array}$ & $11(30.5)$ & $19(54.2)$ & .36 \\
\hline
\end{tabular}

Abbreviation: ICC, intra-cardiac catheterism.

TAB LE 4 Multivariate analysis of maternal anxiety risk factors

\begin{tabular}{|cccc|}
\hline $\mathbf{n}=71$ & Odd ratio & $95 \% \mathrm{Cl}$ & P value \\
\hline RACHS & 11.76 & {$[1.19-116.24]$} & .04 \\
\hline $\begin{array}{l}\text { Paternal anxiety } \\
\text { KM home to surgi- }\end{array}$ & 4.49 & {$[1.04-19.24]$} & .04 \\
$\begin{array}{l}\text { cal center } \\
\text { Comorbidity }\end{array}$ & 0.33 & {$[0.59-1.86]$} & .21 \\
\hline
\end{tabular}

In our study, the level of maternal anxiety was associated with the risk level of the invasive procedure, as measured by the RACHS score for children undergoing cardiac surgery. This may reflect the quantity and quality of information given to parents during the preoperative visit, usually focusing on all potential complications. Indeed, the complexity of medical information provided to parents before their child's surgery, usually correlates with the level of parental anxiety, as shown by Pomicino et al. ${ }^{26}$ Nevertheless, an inappropriate timing of the preoperative visit may play a more important role in parental anxiety than the level of medical information itself. ${ }^{28,29}$
Material and logistical burdens on a family facing a child's chronic illness may also contribute to increase the level of parental anxiety. Indeed, in our study, the level of parental anxiety was higher in families living far from the CHD referral center. In addition to the stress induced by the intervention planned on their child, these parents have to cope with staying in a family accommodation facility, as long as it exists, finding a way to care for their other children, and juggling between their job and hospital. Therefore, specific psychological and social care dedicated to these families should be anticipated. Indeed, each step of the journey to the intervention must be prepared along with the family, in order to minimize their anxiety. ${ }^{30-32}$

Psychological trauma is not uncommon for CHD survivors and healthcare professionals need to focus on the psychosocial care of the family nucleus as a whole, and try to improve the anxiety level of both parents and their child. ${ }^{5}$ Assessing the level of anxiety in routine follow-up, and using a simple tool, stands as the first step toward finding solutions to improve the psychological state of the parents. Indeed, In their study, Landier et al showed that the combination of oral information with written support before surgery diminished the level of parental anxiety when compared to simple oral

\begin{tabular}{|c|c|c|c|}
\hline$n=49$ & $\begin{array}{l}\text { Paternal anxiety } \\
>\text { ou }=\text { à } 8 / 10 \\
N=19\end{array}$ & $\begin{array}{l}\text { Paternal } \\
\text { anxiety > 8/10 } \\
N=30\end{array}$ & $P$ value \\
\hline Maternal AVS, moy $\pm S D$ & $8.3 \pm 1.6$ & $7.4 \pm 2$ & .21 \\
\hline RACHS > $3, n(\%)$ & $7(36.8)$ & $14(46.6)$ & .36 \\
\hline $\begin{array}{l}\text { Distance from home to surgical } \\
\text { center in km [Quart] }\end{array}$ & 121 [73-206] & 104 [25-179] & .17 \\
\hline Comorbidity, $n$ (\%) & $6(31.5)$ & $6(20)$ & .24 \\
\hline Prenatal diagnosis, $n(\%)$ & $8(42.1)$ & $11(36.6)$ & .40 \\
\hline Surgery vs ICC, $n$ (\%) & $12(63.1)$ & $17(56.6)$ & .49 \\
\hline Siblings, $n$ (\%) & $9(47.3)$ & $17(56.6)$ & .56 \\
\hline $\begin{array}{l}\text { Delay between diagnostic and } \\
\text { intervention }>1 \text { year, } n(\%)\end{array}$ & $5(26.3)$ & $8(26.6)$ & .52 \\
\hline
\end{tabular}

TABLE 5 Paternal anxiety $>$ or $=$ to $8 / 10$

Abbreviation: ICC, intra-cardiac catheterism. 
information. ${ }^{33}$ Moreover, Simeone et al showed that a presurgical educational support from a specialist nurse contributed to reduce parental anxiety. ${ }^{34}$ Agostini et al showed a reduction of maternal anxiety after the intervention of clowns the hour before an anesthesia. ${ }^{35}$ Recent advances in new technology may play an important role in following CHD patients and their families in the period around the interventions. For instance, videoconference could provide access facilitation to medical care, especially for patients who live far from specialized tertiary care centers. Previous studies highlighted this type of care and reported reduction of anxiety levels and hospitalization rates in severe $\mathrm{CHD}$. $^{36,37}$

Finally, a recent meta-analysis from 12 studies, reported a positive effect of specific interventions (eg, emotion regulation, social and structural supports) on parental anxiety and stress. ${ }^{38}$

Finding the appropriate amount of medical information that should be given to parents prior to their child's intervention remains a difficult balance to find. On the one hand, medicolegal issues require the physicians to provide extensive and fair information, which may contribute to increase the anxiety level of the parents in a disproportionate way. Indeed, currently $99 \%$ of children with a mild CHD and $97 \%$ of those with a moderate $\mathrm{CHD}$ are discharged alive after first cardiac surgery. ${ }^{39}$ On the other hand, a reassuring medical speech in response to worried parents may seem benevolent but sometimes results in negative effects. For example, Rempel et al have shown that medical advice to parents of children with a hypoplastic left heart syndrome to "treat their child normally" was a bad advice, especially by delaying management of neurodevelopmental issues. ${ }^{40}$ Indeed, parental anxiety may reflect our concerns about the increased risk of neurodevelopmental disorders in children with $\mathrm{CHD},{ }^{41}$ the adverse neurocognitive effect of exposure to repeated anesthesia in children, ${ }^{42}$ or even a potential impaired school performance of their child. ${ }^{43}$

\section{1 | Study limitation}

Our study highlighted that using AVS as a simple tool for anxiety parental assessment was feasible and informative, but further validation studies using specific anxiety questionnaires are required, Indeed, the anxiety AVS has been validated for adults experiencing, themselves, health issues ${ }^{17}$ but no previous study reported AVS anxiety assessment for parents experiencing health issues for their children. As in many observational studies requiring patient-reported outcomes, participation rate was limited (36\% of all hospitalized patients), resulting in inherent selection biases. Moreover, no extensive or qualitative analysis was performed in a way to determine all potential causal factors associated with parental anxiety. Some of those factors might be independent from the child's health condition, such as a higher age of parents, for example. ${ }^{44}$

\section{5 | CONCLUSION}

This study is the first one to evaluate parental anxiety before cardiac intervention using the AVS. The medical and surgical health programs have reached a level of excellence that gives us the opportunity to focus on the quality of psychological and social care. In order to limit the consequences of traumatic events it is essential to improve the quality of life of the parents but also of the children. With the lack of human resources dedicated to the psychological support of the families, we must find ways to use these resources on purpose. AVS must be considered as a screening test for families at high risk of psychological complications. It is, however, important to remember it will never be a diagnostic test.

\section{CONFLICT OF INTEREST}

None.

\section{AUTHORS CONTRIBUTIONS}

All authors critically reviewed and contributed to manuscript writing. Conceived the idea of the project and wrote the initial proposal: Werner Critically advised the writing of the proposal: El Louali, Ovaert, Amedro, Fouilloux

Supported data analysis: El Louali

\section{REFERENCES}

1. Warnes CA, Liberthson R, Danielson GK, et al. Task force 1: the changing profile of congenital heart disease in adult life. J Am Coll Cardiol. 2001;37(5):1170-1175.

2. Khairy P, Ionescu-Ittu R, Mackie AS, Abrahamowicz M, Pilote L, Marelli AJ. Changing mortality in congenital heart disease. J Am Coll Cardiol. 2010;56(14):1149-1157.

3. Bratt E-L, Moons P. Forty years of quality-of-life research in congenital heart disease: temporal trends in conceptual and methodological rigor. Int J Cardiol. 2015;15(195):1-6.

4. Moons P, Luyckx K, Dezutter J, et al. Religion and spirituality as predictors of patient-reported outcomes in adults with congenital heart disease around the globe. Int J Cardiol. 2019;274:93-99.

5. Deng LX, Khan AM, Drajpuch D, et al. Prevalence and correlates of post-traumatic stress disorder in adults with congenital heart disease. Am J Cardiol. 2016;117(5):853-857.

6. Amedro P, Dorka R, Moniotte S, et al. Quality of life of children with congenital heart diseases: a multicenter controlled cross-sectional study. Pediatr Cardiol. 2015;36(8):1588-1601.

7. Amedro P, Basquin A, Gressin V, et al. Health-related quality of life of patients with pulmonary arterial hypertension associated with CHD: the multicentre cross-sectional ACHILLE study. Cardiol Young. 2016;26(7):1250-1259.

8. Jayaram N, Beekman RH, Benson L, et al. Adjusting for risk associated with pediatric and congenital cardiac catheterization: a report from the NCDR IMPACT registry. Circulation. 2015;132(20):1863-1870.

9. Jacobs ML. Pediatric cardiac surgery: the long view. Circulation. 2015;131(4):328-330.

10. Sjostrom-Strand A, Terp K. Parents' experiences of having a baby with a congenital heart defect and the child's heart surgery. Compr Child Adolesc Nurs. 2017;8:1-14. 
11. Woolf-King SE, Alexandra A, Arnold EA, Weiss SJ, Teitel D. Mental health among parents of children with critical congenital heart defects: a systematic review. J Am Heart Assoc. 2017;6(2):e004862.

12. Amedro P, Picot MC, Moniotte S, et al. Correlation between cardio-pulmonary exercise test variables and health-related quality of life among children with congenital heart diseases. Int J Cardiol. 2016;203:1052-1060.

13. Amedro P, Bajolle F, Bertet $\mathrm{H}$, et al. Quality of life in children participating in a non-selective INR self-monitoring VKA-education programme. Arch Cardiovasc Dis. 2018;111(3):180-188.

14. Spijkerboer AW, De Koning WB, Duivenvoorden $\mathrm{HJ}$, et al. Medical predictors for long-term behavioral and emotional outcomes in children and adolescents after invasive treatment of congenital heart disease. J Pediatr Surg. 2010;45(11):2146-2153.

15. Talge NM, Neal C, Glover V, Stress E. Translational research and prevention science network: fetal and neonatal experience on child and adolescent mental health. Antenatal maternal stress and longterm effects on child neurodevelopment: how and why? J Child Psychol Psychiatry. 2007;48(3-4):245-261.

16. Cella DF, Perry SW. Reliability and concurrent validity of three visual-analogue mood scales. Psychol Rep. 1986;59(2 Pt 2):827-833.

17. Lesage F-X, Chamoux A. Use of an analogue visual scale for occupational stress assessment. A review. Arch Mal Prof Environ. 2008;69(5-6):667-671.

18. Facco E, Stellini E, Bacci C, et al. Validation of visual analogue scale for anxiety (VAS-A) in preanesthesia evaluation. Minerva Anestesiol. 2013;79(12):1389-1395.

19. Lesage FX, Berjot S. Validity of occupational stress assessment using a visual analogue scale. Occup Med Oxf Engl. 2011;61(6):434-436.

20. Uzark K, Jones K, Slusher J, Limbers CA, Burwinkle TM, Varni JW. Quality of life in children with heart disease as perceived by children and parents. Pediatrics. 2008;121(5):e1060-e1067.

21. Jenkins KJ, Gauvreau K, Newburger JW, Spray TL, Moller JH, Iezzoni LI. Consensus-based method for risk adjustment for surgery for congenital heart disease. J Thorac Cardiovasc Surg. 2002;123(1):110-118.

22. Facco E, Zanette G, Favero L, et al. Toward the validation of visual analogue scale for anxiety. Anesth Prog. 2011;58(1):8-13.

23. Shirley PJ, Thompson N, Kenward M, Johnston G. Parental anxiety before elective surgery in children. A British perspective. Anaesthesia. 1998;53(10):956-959.

24. Skari H, Malt UF, Bjornland K, et al. Prenatal diagnosis of congenital malformations and parental psychological distress-a prospective longitudinal cohort study. Prenat Diagn. 2006;26(11):1001-1009.

25. Skreden M, Skari H, Malt UF, et al. Long-term parental psychological distress among parents of children with a malformation-a prospective longitudinal study. Am J Med Genet A. 2010;152A(9):2193-2202.

26. Pomicino L, Maccacari E, Buchini S. Levels of anxiety in parents in the $24 \mathrm{~h}$ before and after their child's surgery: a descriptive study. $J$ Clin Nurs. 2018;27(1-2):278-287.

27. Garten L, Maass E, Schmalisch G, Bührer C. O father, where art thou? Parental NICU visiting patterns during the first 28 days of life of very low-birth-weight infants. J Perinat Neonatal Nurs. 2011;25(4):342-348.

28. Kain ZN, Wang SM, Caramico LA, Hofstadter M, Mayes LC. Parental desire for perioperative information and informed consent: a twophase study. Anesth Analg. 1997;84(2):299-306.

29. Spencer C, Franck LS. Giving parents written information about children's anesthesia: are setting and timing important? Pediatr Anesth. 2005;15(7):547-553.
30. Justus R, Wyles D, Wilson J, Rode D, Walther V, Lim-Sulit N. Preparing children and families for surgery: Mount Sinai's multidisciplinary perspective. Pediatr Nurs. 2006;32(1):35-43.

31. LeRoy S, Elixson EM, O'Brien P, et al. Recommendations for preparing children and adolescents for invasive cardiac procedures: a statement from the American Heart Association Pediatric Nursing Subcommittee of the Council on Cardiovascular Nursing in collaboration with the Council on Cardiovascular Diseases of the Young. Circulation. 2003;108(20):2550-2564.

32. Purcell C. Preparation of school-age children and their parents for intensive care following cardiac surgery. Intensive Crit Care Nurs. 1996;12(4):218-225.

33. Landier M, Villemagne T, Le Touze A, et al. The position of a written document in preoperative information for pediatric surgery: a randomized controlled trial on parental anxiety, knowledge and satisfaction. J Pediatr Surg. 2018;53(3):375-380.

34. Simeone S, Pucciarelli G, Perrone $M$, et al. Comparative analysis: implementation of a pre-operative educational intervention to decrease anxiety among parents of children with congenital heart disease. J Pediatr Nurs. 2017;35:144-148.

35. Agostini F, Monti F, Neri E, Dellabartola S, de Pascalis L, Bozicevic L. Parental anxiety and stress before pediatric anesthesia: a pilot study on the effectiveness of preoperative clown intervention. J Health Psychol. 2014;19(5):587-601.

36. McCrossan B, Morgan G, Grant B, et al. A randomised trial of a remote home support programme for infants with major congenital heart disease. Heart Br Card Soc. 2012;98(20):1523-1528.

37. Morgan GJ, Craig B, Grant B, Sands A, Doherty N, Casey F. Home videoconferencing for patients with severe congential heart disease following discharge. Congenit Heart Dis. 2008;3(5):317-324.

38. Doupnik SK, Hill D, Palakshappa D, et al. Coping support interventions during acute pediatric hospitalizations: a meta-analysis. Pediatrics. 2017;140:e20164171.

39. Spector LG, Menk JS, Knight JH, et al. Trends in long-term mortality after congenital heart surgery. J Am Coll Cardiol. 2018;71(21): 2434-2446.

40. Rempel GR, Harrison MJ, Williamson DL. Is "treat your child normally" helpful advice for parents of survivors of treatment of hypoplastic left heart syndrome? Cardiol Young. 2009;19(2):135-144.

41. Marelli A, Miller SP, Marino BS, Jefferson AL, Newburger JW. Brain in congenital heart disease across the lifespan: the cumulative burden of injury. Circulation. 2016;133(20):1951-1962.

42. Andropoulos DB. Effect of anesthesia on the developing brain: infant and fetus. Fetal Diagn Ther. 2018;43(1):1-11.

43. Schneuer FJ, Bentley JP, Davidson AJ, et al. The impact of general anesthesia on child development and school performance: a population-based study. Paediatr Anaesth. 2018;28(6):528-536.

44. Rahimianfar A, Forouzannia S, Sarebanhassanabadi M, et al. Anxiety determinants in mothers of children with congenital heart diseases undergoing cardiac surgery. Adv Biomed Res. 2015;4(1):255. 